\title{
WIND VIBRATION RESPONSE FOR A NEW TYPE OF RETICULATED SHELL
}

\author{
Wang Fan ${ }^{\mathrm{a}}$, Wang Xing \\ School of Architecture and Civil Engineering, Ningbo University of Technology, \\ Ningbo, Zhejiang, 315016, China \\ awyuqi425@163.com
}

Keywords: Wind vibration response, Reticulated shell, Wave superposition method, Time domain analysis

Abstract. Plate-cone reticulated shell is a new type of reticulated shell with good mechanical behaviour and technical economy. Wind-induced vibration response characteristics of plate-cone reticulated shell are studied, the fluctuation wind loads are simulated by using the wave superposition method in the paper. According to the structural behaviour of plate-cone reticulated shell, by using the software ANSYS, wind resistance time domain analysis of plate-cone reticulated shell are carried out through simulating wind field variation around the plate-cone reticulated shell. After comparing the wind dynamic vibration results of the models with different material, some important conclusions for plate-cone reticulated shell are obtained for practical design.

\section{Introduction}

Research for plate-cone reticulated shell in China and abroad is not very sufficient, the research abroad ${ }^{[1]}$ focuses on static analysis and approximate equivalent method. In China, plate-cone reticulated shell is analyzed with composite structures $\mathrm{FEM}^{[2]}$. The dynamic problem of plate-cone reticulated shell is also a very important problem in engineering design, but due to complexity of the structure, the wind vibration response analysis for plate-cone reticulated shell has not been seen at present, not adapting to the needs of engineering application.

In this paper, wind resistance time domain analysis of plate-cone reticulated shell is carried out based on artificial simulation of pulsation wind and numerical wind tunnel test. The wind load factors of plate-cone reticulated shell are discussed under horizontal pulsation wind, the internal force and deflection compared wth no wind, the wind vibration response characteristics of plate-cone reticulated shell are studied deeply.

\section{Wind Factor of Plate-cone Reticulated Shell}

In this paper, by using the wave superposition method, the Davenport horizontal pulsation wind spectrum is simulated. The finite element model of 8 units division for the plate flange is selected for time domain analysis of the following example.

The geometric parameters of plate-cone cylindrical reticulated shell with quadrangular pyramids are: span is $30 \mathrm{~m}$, length is $45 \mathrm{~m}$, vector height is $5 \mathrm{~m}$, thickness is $1.5 \mathrm{~m}$, mesh is divided into $10 \times 15$, the top connecting members are taken as steel pipes of $\Phi 108 \times 5.0$, the triangle plates of cones are taken as steel plates of $3 \mathrm{~mm}$ thickness, the reticulated shell is put on the $10 \mathrm{~m}$ high maintenance structure.

Wind Factor on Central Point of Different Ranks of Cone Plates. By carrying on the statistics and processing of the computed result, the wind load factors of plate-cone cylindrical reticulated shell are attained(Figure 1, Figure 2). In the figures, the abscissa express separately cone serial number along the span direction and along the length direction, the $y$-coordinate express the wind load factors of internal force. 


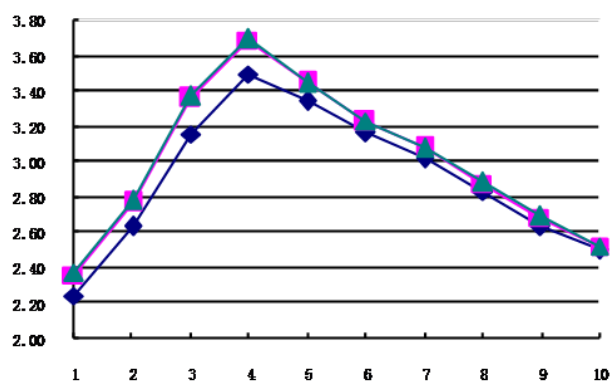

Fig. 1 Wind factor on center point of span of cone plate

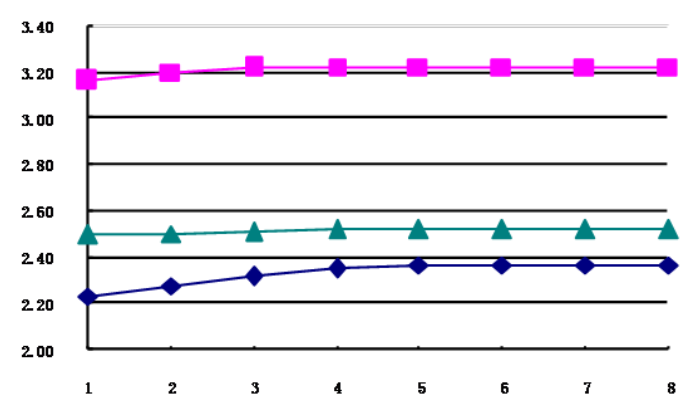

Fig. 2 Wind factor on center point of different different row of cone plate

Wind Factor of Top Member in the Span Direction. By carrying on statistics and processing of results of the above example, internal force wind load factors of top members in the span direction of different rank's cones are obtained

According to the wind load factors of the above model, the wind load factors of this type of model are processed by comparing in this paper, the following wind load factors are recommended:

The wind load factor of top member is suggested as 1.5 .

The wind load factor of cone's plate in the span direction changes along with the shell's height, but the wind load factor in the different span doesn't change largely, therefore the simplified principle is used for the small span shell, the wind load factor is taken as the max 3.7. For the large span shell, the different row of cone's the wind load factor is calculated through the shape factor, and should be selected according to actual computation situation.

\section{Wind Resistance Analysis of Plate-cone Reticulated Shell}

By using the geometry size and the constraints of above example, plate-cone cylindrical reticulated shells with the $3 \mathrm{~mm}$ steel plate and the $18 \mathrm{~mm}$ cement plate are calculated in this paper, firstly the largest wind vibration internal force is compared with the static internal force(Table 1, Table 2), then the dynamic displacement and static displacement are also compared(Table 3).

Table 1 Conversion stress of plate and dynamic- static internal force ratio

\begin{tabular}{|c|c|c|c|c|c|c|}
\hline \multirow{2}{*}{$\begin{array}{l}\text { Stress } \\
\qquad(\mathrm{N} / \mathrm{m} 2) \\
\text { span } \\
\text { number }\end{array}$} & \multicolumn{2}{|c|}{ Static internal force } & \multicolumn{2}{|c|}{ Wind vibration internal force } & \multicolumn{2}{|c|}{$\begin{array}{l}\text { Wind vibration / Static } \\
\text { internal force }\end{array}$} \\
\hline & $\begin{array}{l}3 \mathrm{~mm} \\
\text { plate }\end{array}$ & $\begin{array}{l}18 \mathrm{~mm} \text { cement } \\
\text { plate }\end{array}$ & $\begin{array}{l}3 \mathrm{~mm} \\
\text { plate }\end{array}$ & $\begin{array}{l}18 \mathrm{~mm} \text { cemen } \\
\text { plate }\end{array}$ & plate & $\begin{array}{l}18 \mathrm{~mm} \\
\text { cement } \\
\text { plate }\end{array}$ \\
\hline 1 & $1.52 \mathrm{E}+07$ & $1.61 \mathrm{E}+06$ & $2.54 \mathrm{E}+07$ & $1.45 \mathrm{E}+06$ & 1.662 & 0.900 \\
\hline 2 & $1.41 \mathrm{E}+07$ & $1.38 \mathrm{E}+06$ & $2.25 \mathrm{E}+07$ & $1.17 \mathrm{E}+06$ & 1.599 & 0.847 \\
\hline 3 & $1.26 \mathrm{E}+07$ & $1.12 \mathrm{E}+06$ & $2.30 \mathrm{E}+07$ & $9.87 \mathrm{E}+05$ & 1.832 & 0.883 \\
\hline 4 & $1.08 \mathrm{E}+07$ & $8.63 \mathrm{E}+05$ & $2.73 \mathrm{E}+07$ & $6.83 \mathrm{E}+05$ & 2.523 & 0.791 \\
\hline 5 & $8.99 \mathrm{E}+06$ & $6.41 \mathrm{E}+05$ & $3.88 \mathrm{E}+07$ & $9.58 \mathrm{E}+05$ & 4.313 & 1.495 \\
\hline 6 & $8.99 \mathrm{E}+06$ & $6.41 \mathrm{E}+05$ & $4.84 \mathrm{E}+07$ & $1.30 \mathrm{E}+06$ & 5.387 & 2.025 \\
\hline 7 & $1.08 \mathrm{E}+07$ & $8.63 \mathrm{E}+05$ & $5.18 \mathrm{E}+07$ & $1.55 \mathrm{E}+06$ & 4.788 & 1.796 \\
\hline 8 & $1.26 \mathrm{E}+07$ & $1.12 \mathrm{E}+06$ & $5.44 \mathrm{E}+07$ & $1.85 \mathrm{E}+06$ & 4.326 & 1.652 \\
\hline 9 & $1.41 \mathrm{E}+07$ & $1.38 \mathrm{E}+06$ & $5.29 \mathrm{E}+07$ & $2.06 \mathrm{E}+06$ & 3.751 & 1.494 \\
\hline 10 & $1.52 \mathrm{E}+07$ & $1.61 \mathrm{E}+06$ & $9.49 \mathrm{E}+07$ & $3.44 \mathrm{E}+06$ & 6.223 & 2.134 \\
\hline
\end{tabular}


Table 2 Axial force of top member and dynamic- static internal force ratio

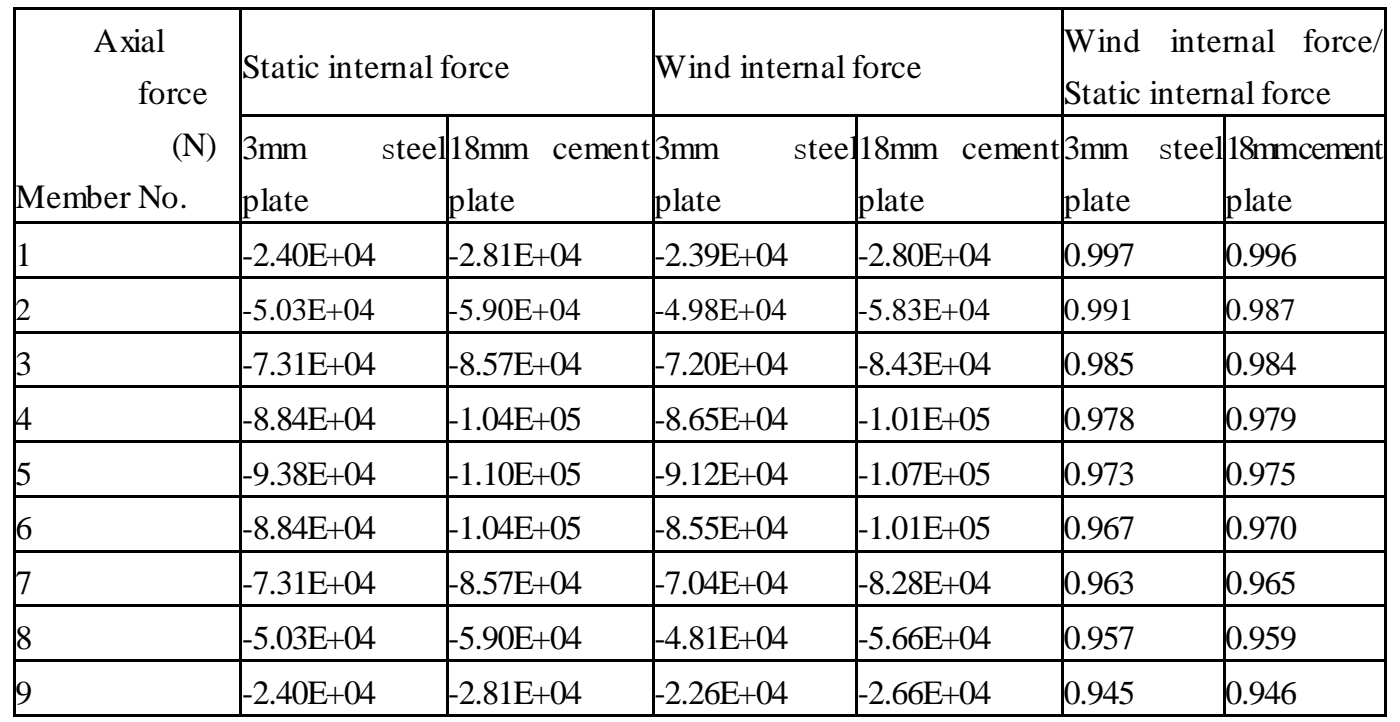

Table 3 Displacement of top node and dynamic- static displacement ratio

\begin{tabular}{|c|c|c|c|c|c|c|c|}
\hline \multirow{2}{*}{$\begin{array}{l}\text { Displacement } \\
\quad(\mathrm{mm}) \\
\text { Node }\end{array}$} & \multicolumn{2}{|c|}{ Static displacement } & \multicolumn{3}{|c|}{ Wind displacement } & \multicolumn{2}{|c|}{$\begin{array}{l}\text { Wind displacement } \\
\text { Static displacement }\end{array}$} \\
\hline & $\begin{array}{l}3 \mathrm{~mm} \\
\text { plate }\end{array}$ & stee $18 \mathrm{~mm}$ cement & plate & stee $18 \mathrm{~mm}$ & $\begin{array}{l}\text { cement } 3 \mathrm{~mm} \\
\text { plate }\end{array}$ & steel & $\begin{array}{l}18 \text { mmceme } \\
\text { nt plate }\end{array}$ \\
\hline 1 & 0.05 & 0.07 & 0.04 & 0.05 & 0.735 & & 0.790 \\
\hline 2 & -1.95 & -2.32 & -2.30 & -2.70 & 1.179 & & 1.167 \\
\hline 3 & -5.22 & -6.28 & -5.19 & -6.24 & 0.994 & & 0.994 \\
\hline 4 & -8.42 & -10.16 & -8.29 & -10.01 & 0.984 & & 0.985 \\
\hline 5 & -10.36 & -12.51 & -10.12 & -12.25 & 0.977 & & 0.979 \\
\hline 6 & -10.36 & -12.51 & -10.06 & -12.19 & 0.972 & & 0.974 \\
\hline 7 & -8.42 & -10.16 & -8.13 & -9.84 & 0.965 & & 0.968 \\
\hline 8 & -5.22 & -6.28 & -5.00 & -6.03 & 0.957 & & 0.960 \\
\hline 9 & -1.95 & -2.32 & -1.83 & -2.18 & 0.939 & & 0.941 \\
\hline 10 & 0.05 & 0.07 & 0.32 & 0.36 & 6.046 & & 5.244 \\
\hline
\end{tabular}

\section{Conclusions}

In this paper, wind vibration response analysis of plate-cone reticulated shell is carried out based on artificial simulation of pulsation wind and numerical wind tunnel test. The wind load factors of plate-cone reticulated shell are discussed under horizontal pulsation wind, the internal force and deflection compared wth no wind, the following conclusions can be attained:

a) The wind load factors of plate-cone reticulated shell change greatly, the internal force wind load factors in the single span change generally along with the height in the span direction of plate-cone reticulated shell, the minimum internal force wind load factor is 2.24 , the maximum is 3.7 , the difference of internal force wind load factors between each span is not great, so for the small span shell, the wind load factor can be taken as the maximum. For the large span shell, the structure can be divided into different zones according to the span direction, the different wind load factors should be selected. 
b) The wind load factors of top members along the span direction range from 1.02 to 1.5 , the wind load factors are larger where the shape factors are larger. Due to the unpredictability of the wind direction, the wind load factors of top members can be taken as 1.5 .

c) Orthogonal square tapered column panel cone reticulated shell under wind load with no wind cone slabs under the cone slabs much difference, mainly due to fluctuating the impact of wind on the result sheet; due to wind load suction effect, so that plate-cone shell structures under static load deflection than a decrease in the deformation of the shell is beneficial impact. Due to the impact of fluctuating wind on the sheet, the internal force of plates under wind load is different greatly with that of no wind load. Wind load's attraction on the structure has beneficial effects on the deflection of the shell.

\section{References}

[1] R.C.Gilkie: A Comparison between the Theoretical and Experimental Analysis of Stressed Skin System ofConstruction in Plastics and Aluminium. Space Structures. London: Blackwell Scientific Publications Ltd (1967).

[2] Wang Xing, Dong Shilin: A study on static characteristics for plate-cone reticulated shell. Building Structures, No.9, Vol.30 (2000), p. 28-30

[3] Huang Bencai: Principles and application of Structural wind analysis. Shanghai: Tongji University Press, China (2001).

[4] Li Yuanqi, Dong Shilin: Wind research for large span reticulated shell. Industrial building, No.5, Vol.31 (2001).

[5] Li Jie: Stochastic structural system. Beijing: Science Press, China (1996).

[6] Wang Zhihong: Simulation research of wind load. Journal of Building Structures, No.1, Vol.15 (1994). 